\title{
Habitual physical activity is not associated with lower cardiovascular risk profile or higher aerobic fitness
}

\author{
Denis Fabrício Valério ${ }^{(1)}$, Arthur Fernandes Gáspari ${ }^{(1)}$, Giovana Vergínea de Souza ${ }^{(1)}$, Cleiton Augusto Libardi(2), \\ Claudia Regina Cavaglieri(1), Mara Patrícia Traina Chacon-Mikahi( ${ }^{(1)}$
}

\begin{abstract}
Introduction: Physical inactivity is considered as one of the factors to increase the risk of developing cardiovascular diseases (CVDs) and decrease aerobic fitness mainly in middle-age. Increased habitual physical activity (HPA) is one of the strategies recommended to reduce physical inactivity. However, it is not known whether middle-age individuals who exclusively perform greater amount of HPA have greater aerobic fitness and / or a lower risk of CVDs. Objective: Verify the association between HPA with the risk of CVDs and aerobic fitness in individuals who only perform HPA. Method: We selected 89 male volunteers, age: $47.4 \pm 5.06$ years, who did not practice systemized physical training. Our measurements were: HPA by the International Physical Activity Questionnaire and Baecke questionnaires, the aerobic fitness by direct assessment of maximal oxygen consumption ( $\mathrm{VO}_{2}$ máx) and the risk of developing cardiovascular disease by the score calculation of General Cardiovascular Risk Profile from Framingham Study. Results: There was no correlation of the HPA level with cardiovascular risk factors, general cardiovascular disease risk and $\mathrm{VO}_{2}$ máx. Moreover, no difference was found between the categorical groups of the IPAQ questionnaire and between the groups, "clusters", calculated from the Baecke questionnaire scores for the variables of cardiovascular risk, general cardiovascular disease risk and $\mathrm{VO}_{2}$ máx. Conclusion: This study have found that the HPA level of middle-aged men is not associated with lower cardiovascular risk profile or higher aerobic fitness, suggesting that only increase HPA may not be enough to promote beneficial adaptations in aerobic fitness and improve risk profile for CVDs. These results may be related to low volume and intensity of HPA, which reinforces the importance of performing physical training with control of these variables for health promotion.
\end{abstract}

KEYWORDS: IPAQ; Baecke; Framingham; physical inactivity

\section{INTRODUCTION}

Cardiovascular diseases (CVDs) are responsible for million of deaths throughout the world. ${ }^{(1,2)}$ It is estimated that 23.3 million individuals will die annually until 2030 because of these diseases. (2) Among the factors that increase the risk of developing CVDs, we can highlight physical inactivity, which has been strongly linked with obesity, hypertension, diabetes, and dyslipidemia. ${ }^{(3,4)}$ Physical inactivity mainly increases starting from middle-age, which is an age range in which approximately $45 \%$ of individuals are considered as inactive. (5) Moreover, together with the high prevalence of inactive individuals, in middle-aged individuals there is a decrease in aerobic fitness that can range from $0.8 \%$ to $1.1 \%$ per year, which can contribute even more to the increase of physical inactivity and the development of CVDs. ${ }^{(6,7)}$

Several strategies have been recommended to reduce the CVDs risk and/or improve aerobic fitness. One established in the literature is to perform systemized /scheduled physical activity with is characterized by the control of training variables as frequency, volume and intensity (i.e. physical training), in order to improve or maintain physical fitness and health. .8-11) $^{-1}$

Another strategy is to increase the habitual physical activity (HPA), which is characterized by the execution of body movements performed in daily life without prior programming and control of volume and intensity as in physical training (e.g. climbing stairs, activities of locomotion). ${ }^{(12,13)}$ It is suggested that HPA may increase caloric expenditure, thus contributing to the control of lipid profile, blood pressure, body fat and blood glucose, as well as improve resting metabolic rate and fat-free mass ${ }^{15}$. In addition, it is possible that the greater caloric expenditure and physical activity level generated by the increase in HPA might promote improved aerobic fitness. ${ }^{(14)}$

However, at the moment, it is not known if individuals who have greater HPA (excluding those who practice physical training) present lower CVDs risk and/or higher aerobic

Corresponding author: Denis Fabrício Valério. Av. Érico Veríssimo, 701, Cidade Universitária Zeferino Vaz, Barão Geraldo, CEP 13.083-851, Campinas, SP, Brazil, telephone +55 193521 6625, e-mail dennisfab@hotmail.com (dennisfabricio82@gmail.com - alternate e-mail)

${ }^{1}$ Universidade Estadual de Campinas (UNICAMP), Campinas (SP), Brazil.

Full list of author information is available at the end of the article.

Financial Support: $\mathrm{CNPq}$

Submission date: 23 August 2016; Acceptance date 28 November 2016; Publication online date: 22 December 2016. 
fitness compared to individuals who have lower HPA. So far, studies looking at the relationship between physical activity and factors related to health and aerobic fitness have not distinguish in their samples individuals who perform only HPA and not physical training (training variables under control), which hinders the actual finding of what is the unique effect of HPA and what is adaptation to physical training. ${ }^{(14-17)}$ Thus, the objective of this study was to verify whether the achievement of only a greater amount of HPA are associated with a lower risk of CVD and greater aerobic fitness compared to individuals who perform a lower amount of HPA in middle-aged men

\section{METHOD}

\section{Participants}

We selected 89 males (age: $47.4 \pm 5.06$ years; body mass: $81.91 \pm 13.51 \mathrm{~kg}$; height: $1.73 \pm 0.06 \mathrm{~m}$ ), who were all non-practitioners of physical training for at least a year. As exclusion criteria we adopted the presence of coronary artery disease, hypertension, limiting osteoarticular diseases and any medication that interfered with the physiological responses during the test of maximum effort. Volunteers who reported through the IPAQ and Baecke questionnaires be performing any type of physical training with control of frequency, volume and intensity in the last 12 months were excluded from the study. All volunteers signed the informed consent approved by the Research Ethics Committee in human beings of the FCM-UNICAMP.

\section{Study design}

On the first visit, we conducted the following assessments: 1) application of the HPA questionnaires; 2) blood pressure assessment and anthropometric assessment; and 3) calculation of General Cardiovascular Risk Profile from Framingham Study. In the second visit, we performed the cardiorespiratory assessment.

\section{Habitual physical activity}

To assess HPA, we used the International Physical Activity Questionnaire (IPAQ) and Baecke questionnaires that report the physical activities carried out in the last week and over the last 12 months, respectively. Volunteers were advised and assisted during the filling out of the questionnaires. Although both questionnaires have the same measuring purpose, we chose to use both to analyze the routine of physical activities performed within twelve months prior to the study, as well as more recent activities held the week before the study. For the IPAQ questionnaire, we used the short version according to the Center for Studies of the Physical Fitness Laboratory of São Caetano do Sul, Brazil CELAFISCS, coordinator of the IPAQ in Brazil; for the analysis of the data on the physical activity level of volunteers, we used the consensus achieved between the CELAFISCS and the
Center for Disease Control (CDC) in Atlanta in 2002, which uses the criteria of frequency and duration (minutes) of physical activity to classify individuals into four categorical classes: very active, active, irregularly active and sedentary, which were compared between themselves. ${ }^{(18,19)}$ Subsequently, the total minutes of physical activity were converted into metabolic equivalent of task (METs), min/week, using the following equation recommended by IPAQ: $3.3 \times$ minutes of physical activity of walking $+4.0 \times$ minutes of physical activity of moderate intensity $+8.0 \times$ minutes of physical activity of vigorous intensity, as described in Silva - Batista et al. (2013). ${ }^{(16)}$

For the Baecke questionnaire, we used the same version validated by Florindo and Latorre (2003), as well as the same methodology used for the calculation of the questionnaire scores. In short, we can understand that the Baecke questionnaire consists of 16 questions covering three physical activity scores for the last 12 months: 1 ) score of occupational physical activities with eight questions, 2) score of physical exercises at leisure with four questions, 3) score of leisure and locomotion physical activities with four questions. For the final calculation of the scores, we took into consideration the intensity of the activity based on the compendium of physical activities of Ainsworth, as well as time (hours per week) and proportion (months per year). ${ }^{(20,21)}$

For the correlation with the variables of cardiovascular risk, general cardiovascular disease risk and aerobic fitness, we used the scores obtained from the questionnaire.

\section{Systemic Blood Pressure}

The determination of the Systemic Blood Pressure (BP) was performed at rest after the volunteers remained in a sitting position for ten minutes in a quiet environment. The measurement was performed by auscultation with mercury sphygmomanometer (Narcosul, Brazil), by an experienced assessor. ${ }^{(22)}$

\section{Anthropometry}

The assessment of body mass was made using scales with accuracy of $0.1 \mathrm{~kg}$ and the height was obtained using a wooden stadiometer (precision of $0.1 \mathrm{~cm}$ ). All the subjects were assessed with appropriate clothing and had their body mass index (BMI) calculated $(\mathrm{kg} / \mathrm{m} 2)$. We measured the waist circumference, at the point of greatest circumference between the last rib and the iliac crest, and the hip circumference, at the maximum extension of the buttocks, both with measuring tape with precision of $0.1 \mathrm{~cm} .^{(23)}$

\section{Assessment of the General Cardiovascular Disease Risk}

The algorithm used for the analysis of the general CVDs risk is called General Cardiovascular Disease Risk Score developed by the Framingham Study. The variables used in the estimation algorithm of this risk are: age, gender, diagnosis for diabetes, 
tobacco use, treated or untreated systolic BP and BMI. ${ }^{(24)}$ The algorithms derived from the Framingham Study are the most widely accepted tools to assess the general CVDs risk and recommended by national and international guidelines. ${ }^{(25)}$

\section{Maximum oxygen consumption}

The assessment of maximal oxygen consumption ( $\mathrm{VO}_{2}$ máx) was performed as described by Libardi et al. (2011). ${ }^{(26)}$ Briefly, the volunteers performed a maximal treadmill exercise protocol (model TM55, Quinton, USA) at the same time as the expired gases were collected from a metabolic analyzer (model CPX-Ultima, Medical Graphics, USA). The protocol consisted of a warming speed of $4 \mathrm{~km} / \mathrm{h}$ for 2 minutes, followed by increases of $0.3 \mathrm{~km} / \mathrm{h}$ every 30 seconds, with a constant slope of $1 \%$ up to physical exhaustion; the recovery was observed for a period of 4 minutes, being the first minute at $5 \mathrm{~km} / \mathrm{h}$, reducing $1 \mathrm{~km} / \mathrm{h}$ every minute. The mean value of the last 30 seconds of the test was considered as the maximum oxygen consumption. The tests were considered as valid when they met the following criteria: respiratory exchange ratio $(R E R)>1.1$, maximum heart rate $(H R)$ within 10 beats of the value predicted by age (220-age) and perceived exertion $>17 . .^{(27)}$

\section{Statistical analysis}

Initially, we tested the normality of the data using the Kolmogorov-Smirnov test. For the correlation analysis between HPA and $\mathrm{VO}_{2}$ máx, body mass, $\mathrm{BMI}$, waist and hip circumference, blood pressure and cardiovascular disease risk, we used the Spearman correlation coefficient. Subsequently, we compared (one-way ANOVA) VO máx, body mass, BMI, waist and hip circumference, blood pressure and general cardiovascular disease risk between the groups formed from the habitual physical activity level of the IPAQ questionnaire (Very Active/Active, Irregularly Active and Sedentary) and between the groups formed from the analysis of K-means clustering from the scores obtained from the Baecke questionnaire. The strategy of cluster grouping was also performed for the IPAQ data obtaining the same results (data not presented), thus we opted to present the categories normally used for this questionnaire. ${ }^{(19)}$ The data were presented as mean and standard deviation, with level of significance at $p<0.05$.

\section{RESULTS}

In the comparison between groups, no differences were found between the groups Very Active/Active vs. Irregularly Active vs. Sedentary of the IPAQ questionnaire for the variables of cardiovascular risk, general cardiovascular disease risk and $V_{2}$ máx $(P<0.05 ;$ Table 1$)$. Moreover, no differences were found between the clusters of the Baecke questionnaire scores for the variables of cardiovascular disease risk and $\mathrm{VO}_{2}$ máx $(p<0.05)$. The data are shown in Table 2.

Finally, there was no correlation between the METs calculated from the IPAQ questionnaire and the Baecke questionnaire scores with the variables of cardiovascular risk, general cardiovascular disease risk and aerobic fitness. The data are shown in Table 3.

\section{DISCUSSION}

This study aimed to verify the association of the HPA level with CVDs risk and aerobic fitness in middle-aged men that do not practice any type of physical training. This strategy allowed the examination of whether different amounts of exclusively

Table 1. cardiovascular risk, general cardiovascular disease risk and aerobic power comparison among the groups Very Active/Active, Irregularly Active and Sedentary based on the IPAQ questionnaire.

\begin{tabular}{|c|c|c|c|c|c|c|c|c|c|c|c|}
\hline \multirow{2}{*}{$N$} & \multicolumn{3}{|c|}{$\begin{array}{c}\text { Very Active } \\
\text { /Active }\end{array}$} & \multicolumn{3}{|c|}{ Irregularly Active } & \multicolumn{3}{|c|}{ Sedentary } & \multirow{2}{*}{ ANOVA } & \multirow{2}{*}{ T-test } \\
\hline & & 21 & & & 48 & & & 20 & & & \\
\hline Total METs & 3552.7 & \pm & 2933.3 & 545.8 & \pm & 607.5 & 113 & \pm & 479.6 & $\mathbf{p}$ & $\mathbf{p}$ \\
\hline Age (years) & 47.7 & \pm & 3.9 & 47 & \pm & 5.4 & 48.3 & \pm & 5.5 & 0.62 & 0.7 \\
\hline Body mass (kg) & 81.8 & \pm & 9.8 & 81.1 & \pm & 15.9 & 84.1 & \pm & 10.5 & 0.73 & 0.49 \\
\hline Height (m) & 1.7 & \pm & 0.1 & 1.7 & \pm & 0.1 & 1.7 & \pm & 0.1 & 0.38 & 0.13 \\
\hline BMI $\left(\mathrm{Kg} / \mathrm{m}^{2}\right)$ & 28 & \pm & 3.1 & 27 & \pm & 4.1 & 27.6 & \pm & 3.2 & 0.58 & 0.7 \\
\hline Waist Circ. (cm) & 93.4 & \pm & 6.9 & 92.3 & \pm & 11.4 & 94.3 & \pm & 8.1 & 0.74 & 0.72 \\
\hline Hip Circ. (cm) & 99.7 & \pm & 7.3 & 99.5 & \pm & 7.9 & 100.4 & \pm & 5.8 & 0.89 & 0.74 \\
\hline Systolic BP (mmHg) & 122.8 & \pm & 8.4 & 120.8 & \pm & 12.4 & 121 & \pm & 11.2 & 0.78 & 0.56 \\
\hline Diastolic BP (mmHg) & 82.7 & \pm & 7.1 & 81.5 & \pm & 9.5 & 81.3 & \pm & 9.3 & 0.84 & 0.57 \\
\hline General CVDs Risk (\%) & 8.3 & \pm & 2.3 & 8 & \pm & 3.2 & 9.3 & \pm & 4.6 & 0.41 & 0.41 \\
\hline $\mathrm{VO}_{2} \max (\mathrm{ml} / \mathrm{Kg} / \mathrm{min})$ & 32.8 & \pm & 5.9 & 33.1 & \pm & 5.9 & 31.9 & \pm & 6.2 & 0.74 & 0.63 \\
\hline
\end{tabular}

One-way ANOVA comparing Very Active/Active X Irregularly Active X Sedentary. T-test comparing Very Active/Active X Sedentary. Circ. = circumference, BP = blood pressure, CVDs $=$ Cardiovascular. Significant difference considered as $p<0.05$ 
Table 2. cardiovascular risk, general cardiovascular disease risk and aerobic power comparison among the clusters for the Baecke questionnaire scores.

\begin{tabular}{|c|c|c|c|c|c|c|c|c|c|c|}
\hline \multirow{2}{*}{$N$} & \multicolumn{3}{|c|}{ Cluster 1} & \multicolumn{3}{|c|}{ Cluster 2} & \multicolumn{3}{|c|}{ Cluster 3} & \multirow{2}{*}{$\frac{\text { ANOVA }}{p}$} \\
\hline & \multicolumn{3}{|c|}{30} & \multicolumn{3}{|c|}{42} & \multicolumn{3}{|c|}{17} & \\
\hline Scores & 5.56 & \pm & 0.54 & 4.15 & \pm & 0.34 & 3.09 & \pm & 0.39 & \\
\hline Age (years) & 47.5 & \pm & 5.36 & 47 & \pm & 5.29 & 48.3 & \pm & 4.03 & 0.67 \\
\hline Body mass (kg) & 78.5 & \pm & 10.88 & 83.12 & \pm & 14.86 & 85.11 & \pm & 13.81 & 0.21 \\
\hline Height (m) & 1.72 & \pm & 0.07 & 1.72 & \pm & 0.06 & 1.76 & \pm & 0.09 & 0.15 \\
\hline BMI $\left(\mathrm{Kg} / \mathrm{m}^{2}\right)$ & 26.61 & \pm & 3.4 & 27.87 & \pm & 3.93 & 27.31 & \pm & 3.55 & 0.37 \\
\hline Waist Circ. (cm) & 90.52 & \pm & 7.82 & 93.56 & \pm & 10.82 & 96.04 & \pm & 9.65 & 0.17 \\
\hline Hip Circ. (cm) & 97.12 & \pm & 6.42 & 100.9 & \pm & 7.8 & 101.2 & \pm & 6.38 & 0.06 \\
\hline Systolic BP (mmHg) & 122.4 & \pm & 11.89 & 120.1 & \pm & 11.49 & 122.4 & \pm & 9.23 & 0.63 \\
\hline Diastolic BP (mmHg) & 83.37 & \pm & 8.67 & 80.45 & \pm & 9.83 & 81.88 & \pm & 5.95 & 0.39 \\
\hline General CVDs Risk (\%) & 8.38 & \pm & 3.62 & 8.12 & \pm & 3.44 & 9.07 & \pm & 2.92 & 0.67 \\
\hline $\mathrm{VO}_{2} \max (\mathrm{ml} / \mathrm{Kg} / \mathrm{mim})$ & 33.8 & \pm & 5.48 & 32.55 & \pm & 5.96 & 31.51 & \pm & 6.56 & 0.42 \\
\hline
\end{tabular}

Circ. = circumference, $\mathrm{BP}=$ blood pressure, $\mathrm{CVDs}=$ Cardiovascular. Significant difference considered as $p<0.05$

Table 3. Correlation between METs of IPAQ questionnaire and Baecke questionnaire scores with the variables of cardiovascular risk, general cardiovascular disease risk and aerobic power.

\begin{tabular}{lll}
\hline & \multicolumn{1}{c}{ IPAQ } & Baecke \\
\hline Body Mass & $\mathrm{R} 0.07 \mathrm{p} 0.53$ & $\mathrm{R}-0.17 \mathrm{p} 0.10$ \\
BMI & $\mathrm{R} 0.16 \mathrm{p} 0.15$ & $\mathrm{R}-0.16 \mathrm{p} 0.14$ \\
Waist Circ. & $\mathrm{R} 0.08 \mathrm{p} 0.43$ & $\mathrm{R}-0.22 \mathrm{p} 0.04$ \\
Hip Circ. & $\mathrm{R} 0.08 \mathrm{p} 0.46$ & $\mathrm{R}-0.22 \mathrm{p} 0.04$ \\
Systolic BP & $\mathrm{R}-0.01 \mathrm{p} 0.93$ & $\mathrm{R} 0.00 \mathrm{p} 0.99$ \\
Diastolic BP & $\mathrm{R} 0.02 \mathrm{p} 0.88$ & $\mathrm{R} 0.05 \mathrm{p} 0.66$ \\
General CVDs Risk & $\mathrm{R}-0.05 \mathrm{p} 0.63$ & $\mathrm{R}-0.09 \mathrm{p} 0.42$ \\
Vo ${ }_{2}$ max & $\mathrm{R} 0.02 \mathrm{p} 0.82$ & $\mathrm{R} 0.15 \mathrm{p} 0.17$ \\
\hline
\end{tabular}

Circ. = circumference, $\mathrm{BP}=$ blood pressure, $\mathrm{CVDs}=$ Cardiovascular. Considered as significant when $p<0.05$

habitual activity would reflect in better health-related parameters and aerobic fitness. As a result, no correlation was found between the HPA level of these individuals with CVDs risk profile or aerobic fitness (data in Table 3). Moreover, there was no difference between the analyzed variables when comparing the groups of higher and lower HPA level (data in Tables 1 and 2). This suggests that greater HPA levels are not sufficient to improve these parameters in middle-aged men.

The HPA has been recommended as a strategy to increase energy expenditure promoting health benefit; however, to the best of our knowledge no work had verified that individuals who carry larger amount of exclusively HPA have better aerobic fitness and / or better risk profile for CVDs. So far, studies looking at the relationship between physical activity, risk factors and physical fitness have not been concerned in distinguish in their samples individuals who perform only HPA and not physical training with control of training variables, which hinders the actual finding of what is the unique effect of HPA and what is adaptation to physical training. ${ }^{(14-17)}$

Silva-Batista et al. (2013) analyzed the relationship between the physical activity level measured by the IPAQ questionnaire with components of physical fitness, among them $\mathrm{VO}_{2}$ máx, and contrary to our result (Table 3 ) they found a positive correlation between these variables. ${ }^{(16)}$ However, in their work there was no distinction between volunteers who performed physical training or just HPA, his sample had individuals with $\mathrm{VO}_{2}$ máx up to $53.6 \mathrm{~mL} \cdot \mathrm{kg}^{-1} \cdot \mathrm{min}^{-1}$. These high values are probably from performing physical training. Thus, these volunteers with high value $\mathrm{VO}_{2}$ máx may be responsible for the positive association between the variables of the study.

Similarly, Park et al. (2009) also found data that differ from ours, showing a significant difference between the values of $\mathrm{VO}_{2}$ máx of individuals considered as active and not physically active. ${ }^{(17)}$ This finding may be related to the physical activity level classification of the individuals; in Park et al. (2009) the sample was classified according to the practice of physical activity (active were those with physical activity frequency greater than or equal to three times a week) not taking into account other aspects that influence the physical activity level and the $\mathrm{VO}_{2}$ máx as the intensity of physical activity. ${ }^{(11,17,28)}$ This form of classification, besides to not being a commonly used methodology for the quantification of the physical activity level (doubly labeled water, questionnaires, accelerometer), does not exclude individuals who may be performing some type of physical training, consequently the higher $\mathrm{VO}_{2}$ máx values in this study can be due to the higher training level and the routine of more intense physical activity of individuals. ${ }^{(11,28)}$

The literature discussed above supports our suggestion that the positive associations between HPA, VO máx and CVDs in these studies may be due to the inclusion of subjects who performed some physical training with control of frequency, 
volume and intensity, and not only a consequence of HPA. Guidelines for physical activity prescription suggest that a minimum of volume and intensity are needed to improve $\mathrm{VO}_{2}$ máx and lower risk of CVDs. ${ }^{(10,29)}$ Just increase the amount of HPA may be insufficient to achieve that minimum necessary and generate positive adaptations, fact reinforced by our results.

Thus, the practice of physical training with greater control over the volume and intensity may be more effective for improving aerobic fitness and risk profile for CVDs. Studies have shown that performing more intense physical exercise promotes greater increase in $\mathrm{VO}_{2}$ máx compared to less intense. $(11,28)$ Nybo et al. (2010) conducted a study compared the effects of performing high-intensity interval training (HIIT) with the continues moderate training on $\mathrm{VO}_{2}$ máx, and showed greater increase for the HIIT group. ${ }^{(11)}$ In addition to the higher increase in $\mathrm{VO}_{2}$ máx studies have observed that more intense exercise are more effective in reducing the risk of CVDs, demonstrating an inverse relationship between the intensity of exercise and the risk of CVDs, further highlighting the importance of this variable for improvement $\mathrm{VO}_{2}$ máx and risk profile for CVDs. $(30,31,32)$

Moreover, Tanasescu et al. (2002) in their study that included 44,452 men aged 40-75 years has shown that performing intense physical activity promotes greater improvements in the risk of CVDs regardless increase in MET-hours spent on physical activity, supporting our suggestion that only increase caloric expenditure by conducting larger amount of HPA may not be enough to promote improvements in the risk of CVDs. ${ }^{(31)}$

Not less important, our study also has limitations as the use of questionnaires to measure the HPA, and the absence of a group that performed physical training to direct compare the efficacy pf HPA and physical training. So, we suggest that other studies analysis the association of HPA, CVDs risk and the aerobic fitness measuring the level of HPA using other direct measurements; and also compare individuals that carry out physical training with the ones that exclusively perform HPA with longer monitoring time.

\section{CONCLUSIONS}

In conclusion our results demonstrate that different levels of HPA, measured by the IPAQ and Baecke questionnaires, in middle-aged men who did not practice physical training, and, therefore, is solely the result of changes in HPA, are not associated with lower cardiovascular risk profile or higher aerobic fitness. This result is reinforced by the lack of differences between the values of $\mathrm{VO}_{2}$ máx and variables that make up the CVDs risk profile of the most active groups when compared to the less active groups. We suggest that positive associations between these variables fond in other studies are due to the inclusion of individuals who perform some type of physical training in the samples studied. This fact complicates the analysis of the association between exclusively habitual physical activity and aerobic fitness or CVDs risk profile, in addition to prevent observations on whether changes in the practice of HPA are sufficient to produce benefits in relation to these health parameters. Finally, we suggest that only increase HPA may not be enough to promote beneficial adaptations in aerobic fitness and improve risk profile for CVDs due to low volume and intensity, which reinforces the importance of conducting physical training for health promotion.

\section{Acknowledgments}

The authors extend their thanks to all volunteers who participated in this study. Dr. Jose Rocha, Discipline Cardiology, Dept. medical clinic, FCM. The corresponding author would like to express gratitude to National Council for Scientific and Technological Development (CNPq).

\section{CONFLICTS OF INTEREST}

The authors declare that they have no conflicts of interest in this work

\section{AUTHOR DETAILS}

${ }^{2}$ Universidade Federal de São Carlos (UFSCAR) São Carlos (SP), Brazil.

\section{REFERENCES}

1. Go AS, Mozaffarian D, Roger VL, Benjamin EJ, Berry JD, Borden WB, et al. On behalf of the American Heart Association Statistics Committee and Stroke Statistics Subcommittee. Heart disease and stroke statistics-2013 update: a report from the American Heart Association. Circulation. 2013;127:e6-e245.

2. http://www.who.int/cardiovascular_diseases/en/ (Accessed: June 26, 2015).

3. Lee IM, Shiroma EJ, Lobelo F, Puska P, Blair SN, Katzmarzyk PT. Effect of physical inactivity on major non-communicable diseases worldwide: an analysis of burden of disease and life expectancy. Lancet. 2012;380:219229.

4. Mora S, Cook N, Buring JE, Ridker PM, Lee IM. Physical activity and reduced risk of cardiovascular events: potential mediating mechanisms. Circulation. 2007;116:2110-2118.

5. Hallal PC, Andersen LB, Bull FC, Guthold R, Haskell W, Ekelund U. Global physical activity levels: surveillance progress, pitfalls, and prospects. Lancet. 2012;380:247-257.

6. Spirduso,W. Physical Dimensions of Aging. 1st ed. Champaign: Human Kinetics, 1995.

7. Dvorak RV, Tchernof A, Starling RD, Ades PA, DiPietro L, Poehlman ET. Respiratory fitness, free living physical activity, and cardiovascular disease risk in older individuals: a doubly labeled water study. J Clin Endocrinol Metab. 2000;85:957-963.

8. Burich R, Teljigović S, Boyle E, Sjøgaard G. Aerobic training alone or combined with strength training affects fitness in elderly: Randomized trial. Eur J Sport Sci. 2015;15:773-83.

9. Johnson JL, Slentz CA, Houmard JA, et al. Exercise training amount and intensity effects on metabolic syndrome (from Studies of a Targeted Risk Reduction Intervention through Defined Exercise). Am J Cardiol. 2007;100:1759-1766.

10. ACSM Position Stand on The Recommended Quantity and Quality of Exercise for Developing and Maintaining Cardiorespiratory and Muscular Fitness, and Flexibility in Adults. Med. Sci. Sports Exerc. 1998;30:975-991.

11. Nybo L, Sundstrup E, Jakobsen MD. High-intensity training versus traditional exercise interventions for promoting health. Med. Sci. Sports Exerc. 2010;42:1951-1958. 
12. Booth FW, Roberts CK, Laye MJ. Lack of exercise is a major cause of chronic diseases. Compr Physiol 2012;2:1143-1211.

13. Silva RB, Costa-Paiva L, Pinto Neto AM, Braga AA, Morais SS. Atividade física habitual e risco cardiovascular na pós-menopausa. Revista Associação Médica Brasileira 2006;52:242-246.

14. Wareham NJ, Hennings SJ, Byrne CD, Hales CN, Prentice AM, Day NE. A quantitative analysis of the relationship between habitual energy expenditure, fitness and the metabolic cardiovascular syndrome. $\mathrm{Br} \mathrm{J}$ Nutr. 1998;80:235-241.

15. Gilliat-Wimberly M, Manore MM, Woolf K, Swan PD, Carroll SS. Effects of habitual physical activity on the resting metabolic rates and body compositions of women aged 35 to 50 years. J Am Diet Assoc. 2001;101:1181-1188.

16. Silva-Batista C, Urso RP, Lima Silva AE, Bertuzzi R. Associations between fitness tests and the international physical activity questionnaire-short form in healthy men. J Strength Cond Res. 2013;27:3481-3487.

17. Park MS, Chung SY, Chang Y, Kim K. Physical activity and physical fitness as predictors of all-cause mortality in korean men. J Korean Med Sci. 2009;24:13-19.

18. Matsudo S, Araujo T, Matsudo V, Andrade D et al. Questionário Internacional de Atividade Física (IPAQ): Estudo de Validade e reprodutibilidade no Brasil. Rev Bras Ativ Fís Saúde. 2001;6:6-18.

19. http://www.celafiscs.institucional.ws/. (Accessed: May 17, 2013).

20. Florindo AA, Latorre MR. Validação e reprodutibilidade do questionário de Baecke de avaliação da atividade física habitual em homens adultos. Rev Bras Med Esporte. 2003;9:121-128.

21. Ainsworth BE, Haskell WL, Whitt MC, et al. Compendium of physical activities: an update of activity codes and MET intensities. Med Sci Sports Exerc. 2000;32:498-504.

22. Sposito AC, Caramelli B, Fonseca FA, et al. [IV Brazilian Guideline for Dyslipidemia and Atherosclerosis prevention: Department of Atherosclerosis of Brazilian Society of Cardiology]. Arq Bras Cardiol. 2007;88:2-19.
23. Heyward VH. ASEP methods recommendation: body composition assessment. JEP online. 2001;4:1-12.

24. D'Agostino RB Sr, Vasan RS, Pencina MJ, et al. A General Cardiovascular Risk Profile for Use in Primary Care: The Framingham Heart Study. Circulation. 2008;117:743-753.

25. ATP III. Executive Summary of The Third Report of The National Cholesterol Education Program (NCEP) Expert Panel on Detection. Evaluation. And Treatment of High Blood Cholesterol In Adults (Adult Treatment Panel III). JAMA. 2002;285:2486-2497.

26. Libardi CA, Souza GV, Gápari AF, et al. Effects of concurrent training on interleukin-6, tumour necrosis factor-alpha and C-reactive protein in middle-aged men. J Sports Sci. 2011;24:1573-1581.

27. Borg GAV, Noble BJ. Perceived exertion. In: Wilmore JH, editor. Exercise and Sport Sciences Reviews. Academic Press. 1974;2:131-153.

28. Ciolac EG, Bocchi EA, Bortolotto LA, et al. Effects of high-intensity aerobic interval training vs. moderate exercise on hemodynamic, metabolic and neuro-humoral abnormalities of young normotensive women at high familial risk for hypertension. Hypertens Res. 2010;33:836-843.

29. Haskell WL, Lee IM, Pate RR, et al. Physical activity and public health: updated recommendation for adults from the American College of Sports Medicine and the American Heart Association. Med Sci Sports Exerc. 2007;39:1423-1434.

30. Lee IM, Sesso HD, Oguma Y, Paffenbarger RS Jr. Relative intensity of physical activity and risk of coronary heart disease. Circulation. 2003;107:1110-1116.

31. Tanasescu M, Leitzmann MF, Rimm EB, Willett WC, Stampfer MJ, Hu FB. "Exercise type and intensity in relation to coronary heart disease in men. JAMA 2002; 288:1994-2000.

32. Ciolac EG. High-intensity interval training and hypertension: maximizing the benefits of exercise?. Am J Cardiovasc Dis. 2012; 2: 102-110. 